\title{
Cholestyramine as monotherapy for Graves' hyperthyroidism
}

Singapore Med J 2016; 57(11): 644-645 doi: 10.11622/smedj.2016177

Dear Sir,

A 36-year-old Chinese woman presented to our hospital with two days of fever associated with diarrhoea and sore throat. She had been diagnosed with Graves' disease one month prior to presentation and had been taking carbimazole $30 \mathrm{mg}$ daily from the time of diagnosis. The patient had leucopenia neutropenia, and elevated C-reactive protein and procalcitonin. Computed tomography of the neck showed tonsillar abscess (Table I). The patient completed two weeks of piperacillin/tazobactam followed by three weeks of oral amoxicillin/clavulanic acid. The abscess resolved during the otorhinolaryngology follow-up.

Thyroid function test showed primary hyperthyroidism. Due to the patient's borderline blood pressure, beta blockers were not administered. Thionamides were contraindicated due to agranulocytosis. Cholestyramine $4 \mathrm{~g}$ every six hours was used to treat hyperthyroidism. Five days after admission, propranolol $10 \mathrm{mg}$ twice daily was introduced when the patient's blood pressure stabilised. Both medications were continued until the patient underwent radioiodine treatment. Her free thyroxine level improved significantly within five days, but her thyroid-stimulating hormone levels improved at a much slower rate (Table II). The patient's condition improved without the use of thionamide and she was discharged after two weeks. She underwent radioiodine treatment ten days after discharge. Thyroxine replacement was started for post-radioiodine hypothyroidism.

Table I. Laboratory test results.

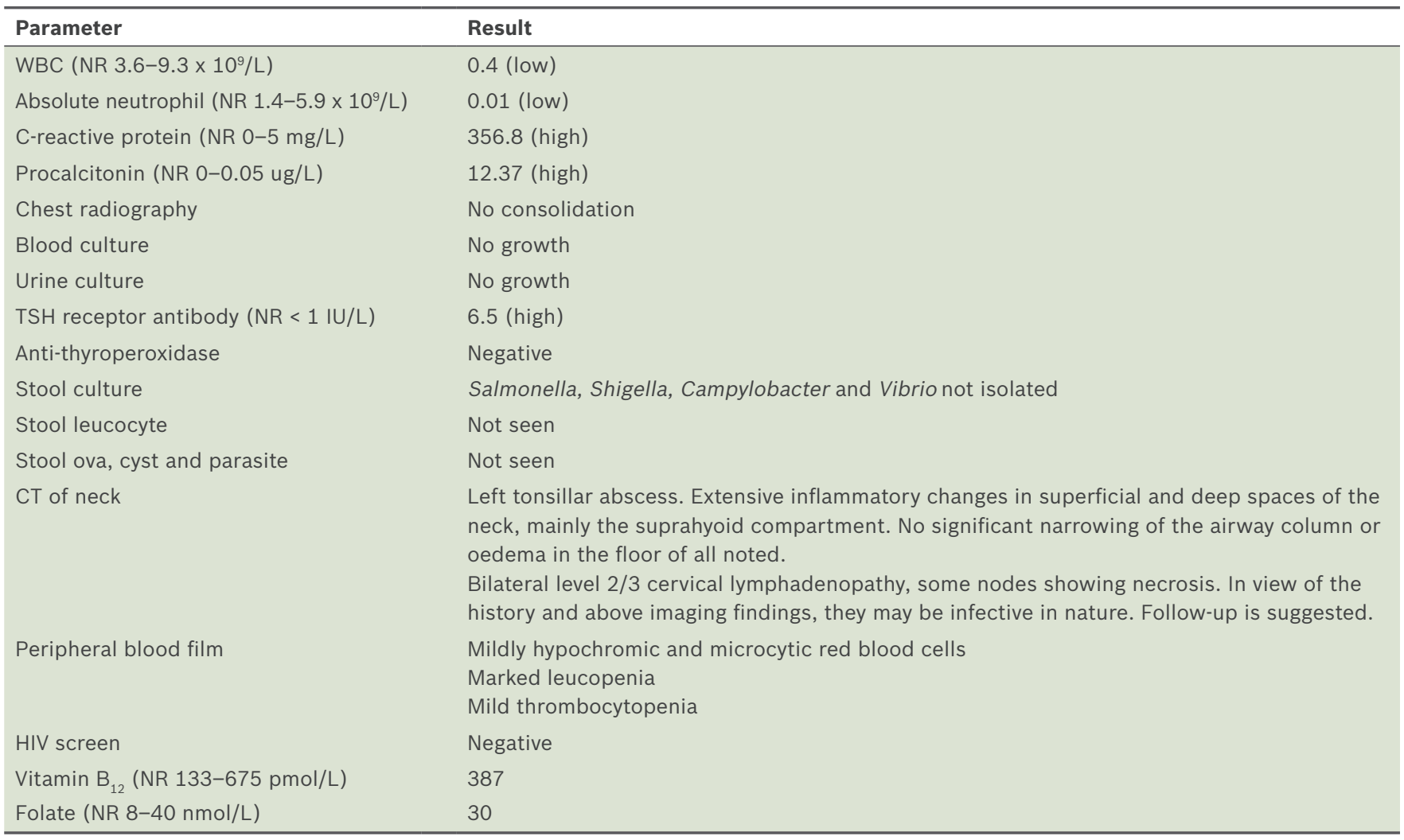

CT: computed tomography; HIV: human immunodeficiency virus; NR: normal range; TSH: thyrotropin; WBC: white blood cell

Table II. Thyroid function test trend.

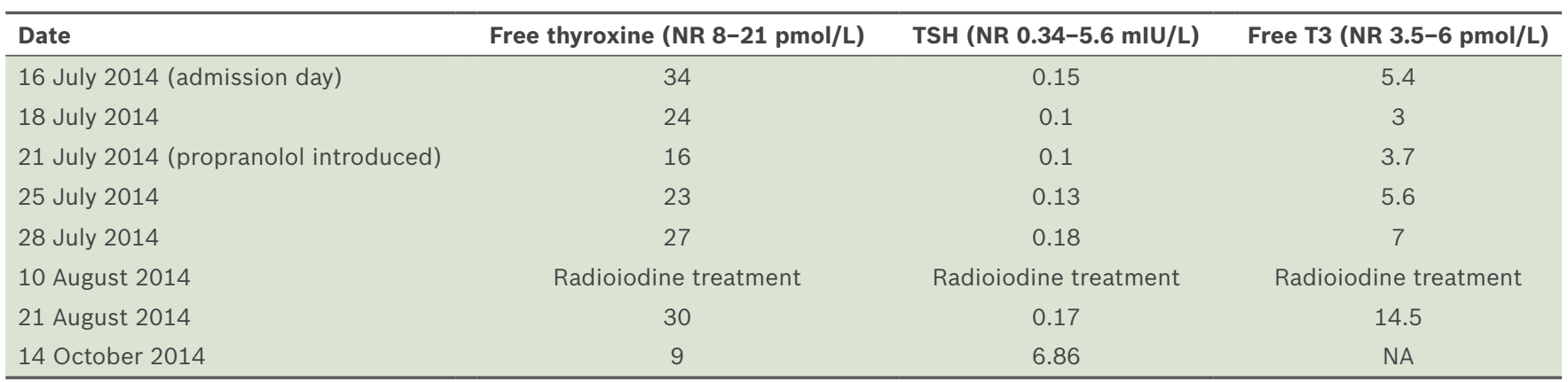

NA: not applicable; NR: normal range; TSH: thyrotropin 
Table III. Full blood count trend.

\begin{tabular}{|c|c|c|c|c|}
\hline Date & $\begin{array}{c}\text { WBC } \\
\left(\text { NR } 3.6-9.3 \times 10^{\circ} / L\right)\end{array}$ & $\begin{array}{l}\text { Absolute neutrophil } \\
\text { (NR 1.4-5.9 × 10\%/L) }\end{array}$ & $\begin{array}{c}\text { Haemoglobin } \\
\text { (NR 11-15 g/dL) }\end{array}$ & $\begin{array}{c}\text { Platelet } \\
\left(\text { NR } 170-420 \times 10^{9} / \text { L) }\right.\end{array}$ \\
\hline 31 May 2014 & 6.12 & 2.85 & 12.4 & 271 \\
\hline 16 July 2014 (admission day) & 0.2 & 0.01 & 10.7 & 116 \\
\hline 17 July 2014 & 0.4 & 0 & 10.9 & 99 \\
\hline 18 July 2014 & 0.4 & 0.04 & 9.1 & 85 \\
\hline 19 July 2014 & 0.7 & 0.01 & 9.4 & 83 \\
\hline 20 July 2014 & 0.8 & 0.05 & 10.9 & 128 \\
\hline 21 July 2014 & 0.7 & 0.05 & 9.2 & 162 \\
\hline 22 July 2014 & 0.8 & 0.02 & 9.4 & 210 \\
\hline 23 July 2014 & 1.0 & 0.05 & 10.9 & 283 \\
\hline 24 July 2014 & 1.7 & 0.14 & 10.5 & 369 \\
\hline 25 July 2014 & 2.0 & 0.56 & 10.5 & 408 \\
\hline 26 July 2014 & 4.6 & 1.95 & 10.6 & 482 \\
\hline 28 July 2014 & 6.3 & 3.16 & 9.7 & 506 \\
\hline
\end{tabular}

NR: normal range; WBC: white blood cell

Studies have shown that in patients with Graves' hyperthyroidism, cholestyramine used in combination with thionamide can lead to a more rapid decline in thyroid hormone levels than with standard therapy alone. ${ }^{(1,2)}$ Cholestyramine was also effective in Graves' hyperthyroidism and iodine contrast-induced hyperthyroidism that was refractory to conventional treatment. ${ }^{(3)}$ However, data on cholestyramine as a monotherapy for hyperthyroidism is limited. De Luis et al reported the successful use of cholestyramine alone in treating thyroxine overdose-induced hyperthyroidism. ${ }^{(4)}$ Lin et al reported a case of interferon alpha- and possibly iodine contrast-induced hyperthyroidism, which was successfully treated with cholestyramine alone. ${ }^{(5)}$ Our literature search did not find any data on cholestyramine monotherapy for Graves' hyperthyroidism.

Cholestyramine enhances the enterohepatic excretion of thyroxine. ${ }^{(5)}$ Lin et al stated that "complete normalisation of free thyroid hormones and notable symptom improvement have occurred within one week of instituting cholestyramine" ${ }^{(5)}$ The optimal dosage is $4 \mathrm{~g}$ 2-4 times daily for four weeks. ${ }^{(5)}$ The patient was neutropenic for ten days (Table III) despite daily dosing of granulocyte colonystimulating factor and cessation of carbimazole. Blood film showed no blast/dysplasia. Her neutrophil count prior to carbimazole initiation was normal. Agranulocytosis typically occurs within 1-2 months of thiamazole administration and resolves in 1-2 weeks after drug cessation. ${ }^{(6)}$ Due to her presentation, drug-induced neutropenia was the most likely diagnosis. Improving cytopenia with sepsis treatment was possible but less likely.

Thionamides were contraindicated in this patient. Glucocorticoids, which are part of the standard treatment for thyroid storm, were an option. However, they could complicate the ongoing sepsis and thus were not used. This case showed that cholestyramine is an effective monotherapy for Graves' hyperthyroidism when thionamides are contraindicated. Our study raises the question of whether cholestyramine should be introduced routinely and from the start as part of treatment for Graves' hyperthyroidism or even thyroid storm.

Yours sincerely,

Chaozer $\underline{E r}^{1}$, Ashish Anil $\underline{\text { Sule }}^{1}$

${ }^{1}$ Department of General Medicine, Tan Tock Seng Hospital, Singapore. erchaozer@gmail.com

\section{References}

1. Kaykhaei MA, Shams M, Sadegholvad A, Dabbaghmanesh MH, Omrani GR. Low doses of cholestyramine in the treatment of hyperthyroidism. Endocrine 2008; 34:52-5.

2. Tsai WC, Pei D, Wang TF, et al. The effect of combination therapy with propylthiouracil and cholestyramine in the treatment of Graves' hyperthyroidism. Clin Endocrinol (Oxf) 2005; 62:521-4.

3. Alswat KA. Role of Cholestyramine in Refractory Hyperthyroidism: A Case Report and Literature Review. Am J Case Rep 2015; 16:486-90.

4. de Luis DA, Dueñas A, Martin J, et al. Light symptoms following a high-dose intentional L-thyroxine ingestion treated with cholestyramine. Horm Res 2002; $57: 61-3$.

5. Lin D, Suwantarat N, Bornemann M. Cholestyramine for thyrotoxicosis? J Fam Pract 2013; 62:E1-2.

6. Mohan A, Joseph S, Sidharthan N, Murall D. Carbimazole-induced agranulocytosis. J Pharmacol Pharmacother 2015; 6:228-30. 